\title{
A Transição da Universidade ao Mercado de Trabalho na Ótica do Jovem
}

The transition from university to the work market in the young's view

Simone Lopes de Melo Faculdade de Ciências, Cultura e Extensão do RN

Livia de Oliveira Borges

Universidade Federal do Rio Grande do Norte

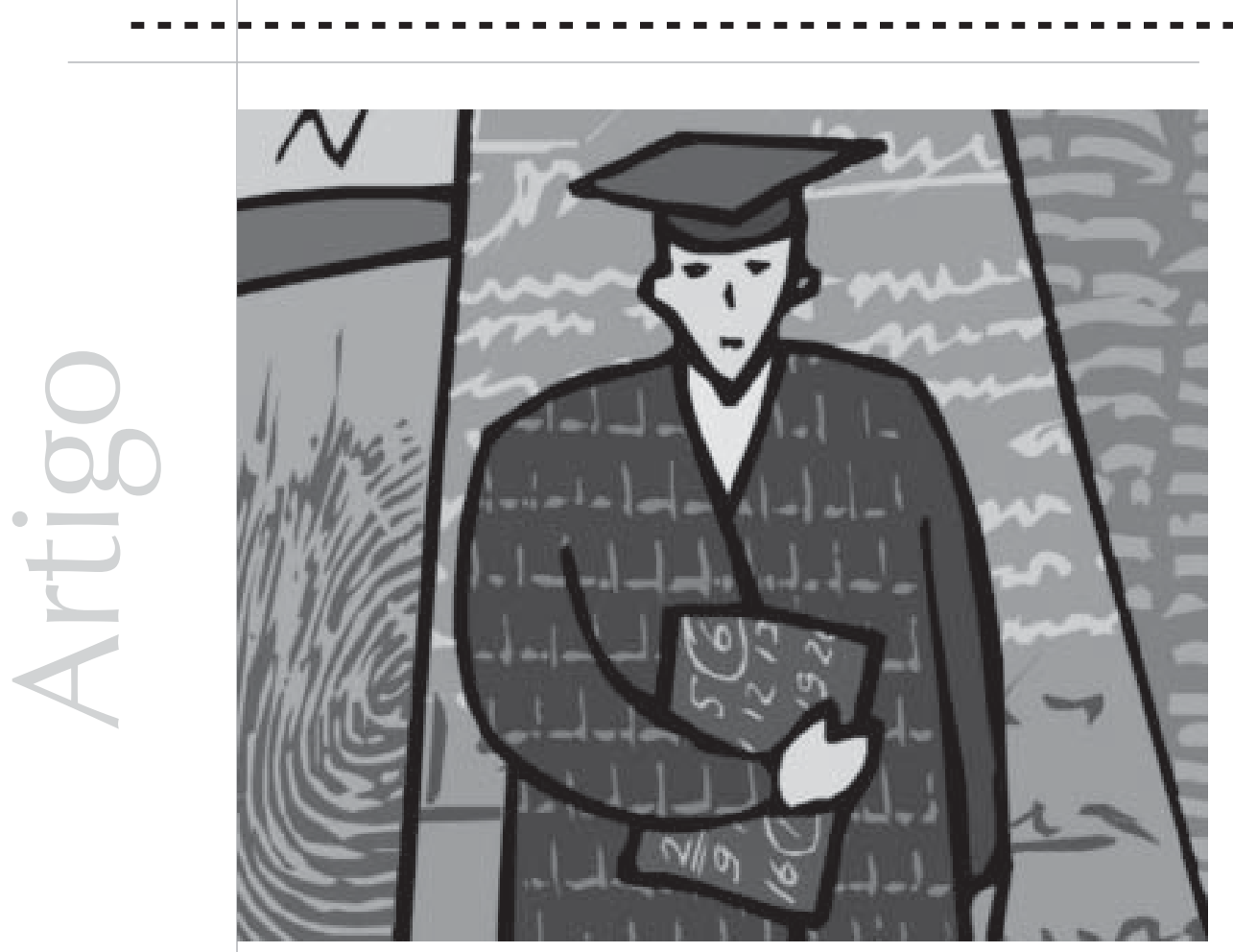




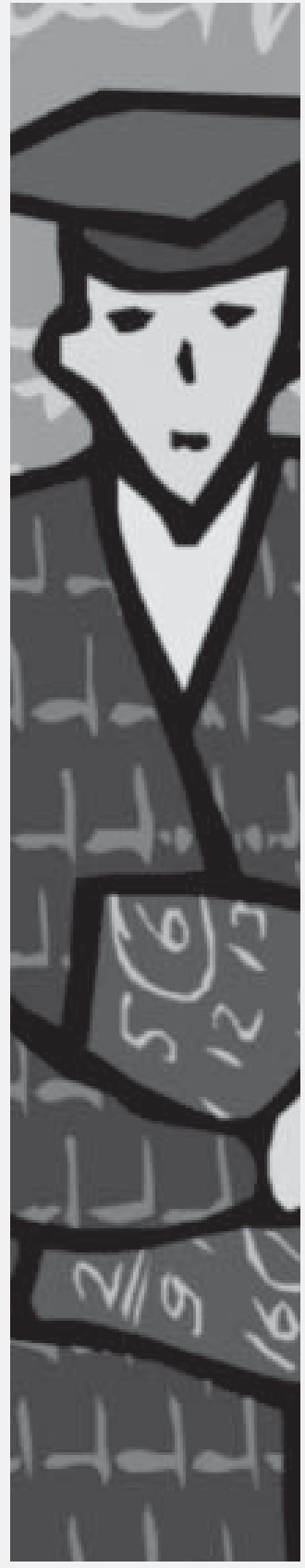

Resumo: O presente estudo tem o objetivo de contribuir para aprofundar a compreensão sobre a vivência de grupos específicos de jovens no que se refere à transição universidade-mercado de trabalho. Realiza-se análise empírica, por meio de corte transversal de dois segmentos de jovens (graduandos e recém-graduados), de acordo com o grau universitário. Entre os resultados da análise de conteúdo das entrevistas de vinte jovens, observa-se que predominam semelhanças entre os dois grupos quanto aos aspectos transição universidade-mercado de trabalho, dificuldades e facilidades de conseguir emprego, avaliação da universidade e do mercado de trabalho, imagem da profissão e projetos futuros de trabalho. Tais semelhanças revelam que a experiência de estágio, pela qual estes passam antes de se tornarem profissionais com nível superior, pode favorecer uma visão mais realista do mercado de trabalho e uma avaliação mais crítica da Universidade diante de um momento decisivo para o jovem em transição.

Palavras-chave: juventude, Universidade, mercado de trabalho, análise de conteúdo.

Abstract: The objective of the present study is to contribute for the deepening of the understanding on the specific young groups' experience in relation to the transition University-work market. An empirical analysis through a transversal split of two segments of young people (those graduating and recent graduates) was done, according to their University level. Among the analysis results, based on the interviews of 20 young people, it was noted that similarities predominate between the two groups about aspects of the transition from the University to the work market, difficulties and ease in acquiring employment, evaluation of the University and the work market, the image of the profession and future job prospects. Such similarities suggest that the training period spent by these individuals before becoming professionals with a higher education would do well to include a more realistic vision of the work market and a more critical evaluation of the University at this crucial moment in the life of a young person in transition.

Key words: young, University, work market, content analysis. 
"Muitas vezes, faltam

informações aos jovens e a quem lida com eles para melhor enfrentar os desafios e/ou amenizar o impacto das dificuldades na transição universidademercado de trabalho".

Araújo; Sarriera, 2004; Schiessl; Sarriera, 2004.
Alguns jovens frustram-se em suas expectativas de ingresso e de estabilidade rápida no mercado de trabalho após a graduação. Eles precisam, então, reformular seus projetos de vida, adotando outras trajetórias, tais como a opção de um novo curso universitário ou de uma pós-graduação, o retardamento da constituição de nova família, a aceitação de um emprego de menor remuneração para a aquisição da experiência na profissão, a ocupação de um emprego em uma área diferente de sua formação ou a busca de trabalho em outras cidades ou países (Araújo e Sarriera, 2004).

Muitas vezes, faltam informações aos jovens e a quem lida com eles para melhor enfrentar os desafios e/ou amenizar o impacto das dificuldades na transição universidademercado de trabalho (Araújo; Sarriera, 2004; Schiessl; Sarriera, 2004). Para aprofundar a compreensão desse processo tal como é vivenciado atualmente por grupos específicos de jovens, realizou-se a pesquisa explorandose as suas percepções sobre o processo de transição da universidade ao mercado de trabalho por grau universitário (graduando ou recém-graduado) dos mesmos. O presente artigo relata, então, a referida pesquisa, e tem início com a síntese da revisão bibliográfica sobre o fenômeno juventude e a transição da universidade ao mercado de trabalho. Em seguida, descreve-se o método e, por fim, relatam-se os resultados encontrados e as conclusões formuladas.

\section{O fenômeno juventude}

\section{na atualidade}

Para a consecução do objetivo da presente pesquisa, é necessária uma clara identificação do indivíduo jovem ou a sua diferenciação de indivíduos que vivem outros processos e/ou etapas da vida. Cardoso e Sampaio (1995), revisando a bibliografia sobre o tema juventude, identificaram dois enfoques presentes na Sociologia: (1) a generalização e (2) a especificidade das juventudes. No primeiro, a ênfase recai sobre a idéia genérica de juventude enquanto "geração" propulsora de mudanças sociopolíticas e culturais de épocas marcadas por grandes acontecimentos históricos (tais como as décadas de 1960 e 1970). No segundo enfoque, defendido pelas autoras do presente artigo, a juventude é vista em seu caráter diversificado, no qual se focam grupos específicos de jovens cujas experiências concretas de vida os diferenciam e os assemelham de contemporâneos ou de outras gerações.

Em consonância com o segundo enfoque, Quapper-Duarte (2001) critica os significados atribuídos a essa categoria - juventude quando esses partem de versões adultocêntricas (cujo parâmetro central de referência é o adulto), porque estas discriminam formas de viver próprias dos jovens e não consideram as diferenças existentes entre eles. Quapper-Duarte (2001) e Costa (1996) ressaltam que tais diferenças entre os jovens se vinculam às experiências de cada geração e aos contextos específicos e globais aos quais pertencem.

Se os grupos de jovens se diferenciam entre si, os jovens universitários (minoritários no Brasil), no período de transição de uma condição de estudante para profissional, devem ser investigados como um grupo distinto dos demais, identificando-se as particularidades de sua inserção no mercado de trabalho e os obstáculos que vivenciam para manter-se nesse mercado. Dessa forma, o enfoque voltado para a especificidade da juventude é adequado à presente pesquisa. Faz-se a ressalva que, de acordo com tal tendência, não se pretende, nesta pesquisa, generalizar os resultados para todos os jovens universitários, mas explorar as vivências de um grupo específico. 
$\mathrm{Na}$ tentativa de esclarecer o conceito do fenômeno pela diferenciação dos jovens de outros grupos, Sanchis (1997) aponta o risco da imprecisão terminológica quando os psicólogos utilizam as palavras "jovem" e "adolescente" como sinônimos, e menciona a falta de consenso entre os sociólogos quando eles definem o início da juventude após o término do ensino obrigatório (até aos dezesseis anos de idade), mas não oferecem critérios sobre o momento em que se chega à idade adulta. O referido autor admite que a integração precoce ao sistema produtivo implica o alcance do status de adulto em menor tempo de vida, à medida que o jovem busca independência financeira para a sobrevivência. Em contrapartida, o retardamento do ingresso no mercado de trabalho, para a continuação dos estudos, implica a permanência do status de jovem em virtude do adiamento da independência financeira, não sendo possível, então, encontrar todos os jovens dentro dos limites cronológicos estabelecidos pelos economistas. Vários autores (Camarano; Mello; Pasinato; Kanso, 2004; Costa, 1996; Margulis, 2001; Quapper-Duarte, 2001; Sanchis, 1997) criticam a identificação da juventude apenas por meio de um critério estatístico, ou seja, por faixa etária. Quapper-Duarte (2001), adicionalmente, defende o uso da idade social como critério definidor, porque a idade biológica não explica a diversidade de realidades construídas entre os grupos de jovens. Camarano Mello, Pasinato e Kanso $(2004$, p. 6) corroboram o último autor quando definem os jovens como "indivíduos que estão sendo construídos com base nas suas características pessoais e nas informações, experiências e oportunidades propiciadas pela família e pelo contexto social em que vivem, aí incluídas as políticas públicas."

Camarano, Mello, Pasinato e Kanso (2004) ressaltam que a mais comum das imagens da juventude está em associá-la a uma fase de transição, evidência de que os processos de inserção social e econômica dos jovens se transformam com a temporalidade e a historicidade, e que, portanto, a realidade dos jovens de hoje é cada vez mais "determinada por processos de transição desiguais, em que trajetórias diferenciadas exercem papéis diferenciados sobre as diversas maneiras de ser jovem" (Camarano; Mello; Pasinato e Kanso, 2004, p. 4).

Agulló-Tomás (1997) ressalta, então, a complexa tentativa de definição do que seja "ser jovem" na atualidade em decorrência da necessidade de usar vários critérios - como a idade, o status social, econômico e jurídico e o contexto sociocultural - o que impede, assim, a unicidade do emprego do termo e amplia o risco do reducionismo conceitual. Dentro dessa perspectiva, Margulis (2001) atribui à juventude significações superpostas, elaboradas historicamente como reflexo de um processo social de construção. Tal processo ocorreria no interior dos sistemas de significações de cada marco institucional (família, fábrica, escola, partido político, etc.) e definiria as identidades sociais dos sujeitos denominados jovens.

Dessa maneira, concorda-se com a afirmação de Costa (1996), segundo a qual a juventude é um conceito aberto, sendo, portanto, construído no contexto do processo históricocultural, sempre com uma tentativa de aproximação conceitual. Adotou-se, por conseguinte, a definição de Agulló-Tomás (1997), na qual o jovem é aquele indivíduo que, tendo superado a fase da adolescência (através do término das mudanças corporais da puberdade, da aquisição de maturidade sexual, da resolução de crises de identidade, da consolidação do crescimento físico e da personalidade, da maior independência intelectual, etc.), adquiriu condições necessárias, porém insuficientes, para o desempenho das funções de um adulto, uma
Agulló-Tomás (1997) ressalta, então, a complexa tentativa de definição do que seja "ser jovem" na atualidade em decorrência da necessidade de usar vários critérios - como a idade. o status social, econômico e jurídico e o contexto sociocultural - 0 que impede, assim, a unicidade do emprego do termo e amplia o risco do reducionismo conceitual. 
Não havendo outros meios socialmente aceitos para o alcance do status de adulto, o jovem de hoje é aquele que ainda busca a sua identidade profissional, a sua autonomia nas decisões pessoais e profissionais, a independência financeira e a sua participação ativa na sociedade por meio do trabalho. vez que somente será reconhecido socialmente como tal quando possuir um emprego relativamente estável e seguro, ou seja, quando a sua inserção no mercado de trabalho tiver ocorrido de forma plena, após o enfrentamento dos obstáculos socioeconômicos da sociedade em que vive e aqueles advindos da sua relação com o mundo do trabalho.

A partir dessa definição, tomaram-se os seguintes critérios para definir o ser jovem investigado nesta pesquisa: (a) a busca de participação ativa na sociedade, com a superação das mudanças biopsicossociais da adolescência (por exemplo, término da puberdade) e a conscientização cada vez maior do seu papel social; (b) o início da formação de uma identidade profissional, que diz respeito ao contato e ao compromisso com uma determinada área de trabalho; (c) a capacidade decisória sobre sua vida pessoal e profissional, sem, necessariamente, depender da opinião familiar; (d) o processo de construção da independência financeira, para uma possível separação plena da família de origem.

Não havendo outros meios socialmente aceitos para o alcance do status de adulto, o jovem de hoje é aquele que ainda busca a sua identidade profissional, a sua autonomia nas decisões pessoais e profissionais, a sua independência financeira e a sua participação ativa na sociedade por meio do trabalho.

Utilizando tais critérios para identificar os jovens, há uma tendência à variação de faixa etária devido a vários fatores sociohistóricos. Simultaneamente à discussão conceitual que se vem relatando, os autores também vêm assinalando a tendência à prorrogação de tal fenômeno na atualidade (Camarano; Mello; Pasinato e Kanso, 2004; Costa, 1996; Sanchis, 1997; Agulló-Tomás, 1997), o que, por sua vez, suscita questões como: Sempre existiu o fenômeno juventude? Não é possível uma passagem direta da adolescência para a vida adulta? Que aspectos têm, então, contribuído para a prorrogação desse período? O que determina o surgimento e a extensão desse fenômeno na atualidade?

Agulló-Tomás (1997) afirma que tal fenômeno constitui um marco nas transformações da sociedade atual, a partir da II Grande Guerra, decorrentes da explosão demográfica, dos avanços científicos e tecnológicos, das novas ideologias e dos valores socioculturais. $\mathrm{O}$ jovem de meados do século passado vivenciou todo um processo de mudança particular (a liberdade sexual, o surgimento da pílula anticoncepcional, a saída da mulher para o mercado de trabalho, a revolta contra as guerras, as mudanças de comportamento entre gerações, etc.). Para Sanchis (1997), falando sobre o mesmo período conjuntural, dois fatos devem ser destacados na contribuição do delineamento do fenômeno juventude: o incremento da demanda social da educação e a redução da aprendizagem no interior das unidades produtivas.

Em consonância com a concepção de moratória psicossocial de Erickson (1976) sobre a adolescência, mais recentemente, Margulis (2001, p. 43) chama a atenção para a noção de moratória social - "prazo concedido a certa classe de jovens, que lhe permite gozar de uma menor exigência, enquanto completam sua instrução e alcançam sua maturidade social e econômica". É uma condição mais específica de jovens da classe média e alta (com poder econômico e cultural), que se incorporaram à universidade e postergaram sua inserção plena no mercado de trabalho, e, por conseguinte, receberam a legitimidade social de seu tempo livre. O referido autor exclui, da condição de moratória, as pessoas (a maioria de classe baixa) que assumem um emprego e um casamento logo cedo, por considerá-las adultas, além de jovens (marginalizados na sociedade) 
cujo tempo disponível se associa à problemática de exclusão social (do sistema educacional, produtivo, etc.).

A pesquisa de Sampaio, Limongi e Torres (2000) sobre a eqüidade e a heterogeneidade no ensino superior brasileiro corrobora a noção de moratória social de Margulis (2001) quando relata que os jovens em condições de ingresso ao ensino superior (público ou privado) provêm, em geral, de famílias com padrão econômico alto, são mais freqüentemente de cor "branca", e seus pais possuem mais escolaridade, embora acrescentem que, mesmo entre esses jovens, existem diferenças socioeconômicas significativas, distinguindo aqueles que estudam em cursos diurnos ou noturnos e em instituições públicas ou privadas, entre outros aspectos.

Diante do relatado anteriormente, percebese que a exigência social para o alcance de responsabilidades adultas por meio do ingresso no mercado de trabalho é trocada pela exigência de maior qualificação para esse ingresso, seja em virtude das mudanças técnicoorganizacionais ocorridas, seja pela incapacidade da sociedade de lidar com o grande contingente de futuros jovens desempregados (Margulis, 2001; Sanchis, 1997).

Os indicadores educacionais da Pesquisa Nacional por Amostra de Domicílios (PNAD) referentes ao período de 1993 a 2003 revelam que o nível de instrução da população de vinte e cinco anos de idade ou mais (com potencial para ter concluído o nível superior) subiu em 1,2 ano de estudo, de 1993 para 2003. No grupo de vinte a vinte e quatro anos de idade, o número médio de anos de estudo saltou de 6,5 para 8,5, de 1993 para 2003, o que denota uma resposta à exigência de maior qualificação do jovem para o ingresso no mercado de trabalho (IBGE, 2003). Apesar da elevação da escolaridade no grupo jovem, os resultados da PNAD indicam que as taxas de ocupação da população economicamente ativa permaneceram inferiores a partir de 1996 até 2003, se comparados aos níveis da primeira metade da década de 1990, o que confirma o aumento do desemprego no Brasil (IBGE, 2003).

Em virtude dessa conjuntura, Agulló-Tomás (1997) e Sanchis (1997) percebem que responsabilidades consideradas adultas (produtiva, conjugal, doméstica e parental) vão sendo assumidas em momentos diferentes e individuais, além de gerar situações intermediárias dentro da condição de jovem em todas as classes sociais. Tal prorrogação da juventude acaba sendo outra característica do fenômeno. Bercovich e Madeira (1992) previam que, na década de 1990, haveria diminuição das oportunidades de incorporação da juventude ao mercado de trabalho durante um novo período de "onda jovem" (ou seja, um alargamento nas faixas de idade entre quinze e vinte e quatro anos, após um período passado de estreitamento que caracterizaria a pirâmide etária brasileira), fato que ocasionaria mudanças nas condições de vida dos jovens e traria problemas políticos e sociais ao País.

A PNAD comprova que o número de jovens de quinze a vinte e quatro anos de idade permanecerá crescendo (IBGE, 2003), embora houvesse a perspectiva de queda nas taxas a partir de 2000-2005 em virtude da tendência declinante da fecundidade associada à redução da mortalidade no Brasil (IBGE, 1999). Dados coletados da PNAD revelam que o grupo de quinze a dezenove anos de idade tem percentual na população maior $(9,9 \%)$ que as faixas situadas entre zero a catorze anos de idade, mas o seu percentual continua em queda (uma vez que, em 1981, esse percentual era de 11,4\%), aproximando-se do grupo etário de vinte a vinte e quatro anos (9,5\%) que, em 1981, representava 9,1\% da população do Brasil (IBGE, 2003). 
Camarano, Mello, Pasinato e Kanso (2004) revelam que o estudo das condições de vida da população jovem no Brasil se intensificou na década de 1990 por várias razões, dentre elas: o temor de uma explosão demográfica de jovens, a instabilidade do mercado de trabalho, a violência urbana e o aumento do índice de mortalidade por difusão de doenças sexualmente transmissíveis como a AIDS.

A nova "onda jovem" chegou no momento em que o País iniciava seu processo de reestruturação produtiva, com a diminuição do quadro de pessoal das empresas para redução de custos e, em conseqüência, com o desemprego em massa. A exigência de maior qualificação e a necessidade de especialistas para lidar com a adoção de novas tecnologias e formas de gestão contribuíram para o surgimento de novos cursos de pósgraduação nas universidades. Dessa forma, não sendo suficiente concluir o ensino médio e/ ou superior, o período de preparação para a vida adulta vem se tornando cada vez mais longo. Sampaio, Limongi e Torres (2000) cogitam, inclusive, do aumento da demanda para o ensino superior em virtude de diversos fatores, tais como a "onda jovem", o avanço da escolaridade de nível médio entre os jovens e a redução do índice de participação destes no mercado de trabalho.

Além do fator político, principalmente, reforçado pela necessidade de programas sociais voltados para o público jovem, tendo como exemplo o Programa Nacional de Estímulo ao Primeiro Emprego (PNPE) destinado às pessoas de dezesseis a vinte $\mathrm{e}$ quatro anos de idade, e que foi implantado pelo Governo Federal para a geração de oportunidades de trabalho nesse grupo (MTE, 2004), é preciso destacar outros fatores que configuram a realidade de diversos grupos de jovens, como a classe social de origem, que influencia as oportunidades de emprego entre um e outro jovem, pois estas exigem uma rede de relações sociais nem sempre formais; o mercado de consumo globalizado, que aumenta as alternativas e estabelece novos valores de compra, excluindo os jovens que não têm poder aquisitivo; os meios de comunicação, cujo avanço mais significativo é vislumbrado pela internet, que, embora não seja acessível a todo jovem, encontra, nesse público, maior capacidade de processamento rápido de informações.

Em síntese, existem vários aspectos conjunturais que sustentam a prorrogação do fenômeno juventude na atualidade. Tudo o que foi exposto, principalmente a partir de Agulló-Tomás (1997) e Sanchis (1997), corrobora a observação de que há uma ruptura entre o antigo modelo linear de transição do jovem para a vida ativa (adulta) e o atual modelo. No primeiro, tradicional ou clássico, a passagem da escola para o trabalho era geralmente curta, permitindo ao jovem uma rápida emancipação com relação à sua família de origem e à aquisição de uma vida própria. O novo modelo, mais complexo, requer a análise de estilos de vida, de composição de arranjos familiares diferenciados e de trajetórias distintas para a vida adulta, como sustentam Camarano, Mello, Pasinato e Kanso (2004).

\section{A transição da universidade para o mercado de trabalho}

A transição da universidade para o mercado de trabalho é uma das trajetórias centrais para os jovens no caminho da construção da vida adulta, sendo, portanto, o foco de atenção desta pesquisa. Sarriera e Verdin (1996) consideram o período de transição escolatrabalho crítico para o desenvolvimento da juventude, porque certas implicações - como a perda da condição de aluno e do apoio da escola, a perda da influência da família, pela necessidade de o indivíduo construir uma identidade própria, a falta do status de trabalhador e do apoio da empresa - podem 
produzir sentimentos de impotência, de insegurança, de apatia e de desorganização, e, por conseguinte, de adoecimento, de comportamentos anti-sociais ou de fuga da realidade, caso o jovem não esteja preparado e apoiado para a aquisição do status de cidadão ativo e produtivo.

De acordo com Gazo-Figuera (1996), a resolução de momentos-chave, que se constituem em subprocessos de transição ocorridos nos diferentes âmbitos da vida do jovem (na universidade, no trabalho, na família e na comunidade), determina o processo total de transição e conduz o jovem a uma diversidade de trajetórias até a fase adulta. A autora enfatiza que a transição pode processarse antes da graduação, no caso de o universitário (estudante-trabalhador ou trabalhadorestudante) manter um contato formalizado com o mercado de trabalho, mas o alargamento do período escolar no contexto universitário prolonga os processos de inserção social plena, fazendo com que o jovem permaneça em seu lugar de origem e seja financeiramente dependente nos primeiros anos de transição ao mercado de trabalho, para, posteriormente, alcançar a independência total da família.

Dentro de uma perspectiva psicossocial, GazoFiguera (1996) aponta a necessidade de um modelo explicativo do processo de inserção do jovem universitário no mercado de trabalho que articule tanto variáveis contextuais macroeconômicas (binômio oferta quantitativa e qualitativa e demanda do mercado de trabalho) e microeconômicas (a titulação, a qualidade da instituição formadora, a dinâmica particular dos mercados de trabalho, etc.) quanto pessoais (gênero, classe social, procedência geográfica, rendimento acadêmico, formação complementar, imagem do papel profissional, construção da identidade ocupacional, significado subjetivo atribuído ao trabalho e exploração de uma carreira profissional) e que considere o graduado sujeito ativo de sua própria inserção.
Como Sanchis (1997), Gazo-Figuera (1996) entende que a universidade deve assumir um papel de apoio ao estudante para facilitar a inserção no mercado de trabalho. A referida autora sugere, como política educacional, a criação de uma estrutura de informação sobre a dinâmica do mercado de trabalho que sirva de referência e de fundamentação para as decisões institucionais e os projetos profissionais dos estudantes. No âmbito da orientação universitária, Gazo-Figuera (1996) sugere o desenvolvimento de programas de orientação e de intervenção, durante a fase de transição ao mercado de trabalho, que sigam as seguintes recomendações: (a) aplicação em contextos próximos do aluno; (b) treinamento em habilidades de tomada de decisão e busca de emprego; (c) desmitificação de percepções e de conceitos que reforcem a conduta passiva frente ao mercado de trabalho; (d) construção de programas de desenvolvimento pessoal para estudantes com problemáticas específicas; (e) integração a uma política de emprego que facilite a atuação em nível microcontextual. A adoção de alguns desses pontos poderia garantir ao jovem uma passagem mais amena para a vida adulta, fazendo com que ele conseguisse ultrapassar com maior apoio social os obstáculos referentes ao período de transição universidade-mercado de trabalho. Em síntese, importa retomar que tudo que foi exposto corrobora a noção de que a transição universidade-mercado de trabalho é uma das experiências mais marcantes para a juventude à qual o artigo se refere, embora não se constitua na única experiência, mas, ao contrário, seja interdependente de demais experiências e restrita aos jovens que têm acesso à educação superior. Torna-se evidente a relevância do nosso propósito de apreendêla melhor como forma de aprofundar a compreensão desse processo de transição como vivenciado pelos grupos de jovens investigados. 


\section{Método}

\section{Tipo de Pesquisa}

A presente pesquisa de campo consistiu num estudo exploratório e descritivo (Lakatos e Marconi, 1991), cuja análise empírica da transição do jovem de estudante universitário a profissional foi realizada por meio de um corte transversal de dois segmentos de jovens, de acordo com o seu grau universitário (graduandos e recém-graduados), visando a compará-los, com o fim de identificar semelhanças e diferenças nas suas vivências decorrentes do processo de transição.

Tendo em vista a consecução do referido objetivo, elaboraram-se as seguintes questões: Qual a percepção do jovem sobre a transição universidade-mercado de trabalho? Qual a avaliação que o jovem tem da universidade no seu papel de prepará-lo para o mercado de trabalho? Qual a avaliação do jovem sobre o mercado de trabalho? De que apoio o jovem sente necessidade para facilitar sua inserção no mercado de trabalho? Que oportunidades de inserção, a partir da sua profissão, o jovem percebe? Quais são os projetos futuros de trabalho desses jovens universitários?

\section{Participantes}

A pesquisa foi realizada com vinte jovens, sendo nove graduandos e onze recémgraduados, pertencentes a vários cursos (arquitetura, ciências da computação, fisioterapia, Medicina, Direito e Psicologia). O primeiro segmento de jovens era o daqueles que estavam cursando o penúltimo período da sua graduação, sendo que a maioria realizava estágio curricular, em conformidade com os currículos de cada curso, e o segundo segmento, composto por jovens com graduação concluída até um ano antes da realização da pesquisa, que exerciam a sua profissão ou outra atividade ou continuavam os estudos acadêmicos em cursos de pósgraduação. Na formação da amostra, foram eliminados os jovens que tinham alguma experiência anterior de trabalho, uma vez que tal fato poderia causar um viés quanto à percepção do jovem sobre o momento de transição entre a conclusão do curso superior e a inserção no mercado de trabalho.

Instrumento de pesquisa

Foi utilizada, como instrumento de pesquisa, a entrevista com um roteiro de perguntas semi-estruturadas que abrangiam itens referentes às facetas do fenômeno em estudo: a transição universidade-mercado de trabalho, as dificuldades e facilidades de conseguir emprego, a avaliação da universidade, a avaliação do mercado de trabalho e os projetos futuros de trabalho, e, como variável antecedente, a transição do jovem de estudante universitário a profissional, que possuía, como indicador, o grau universitário do jovem.

Procedimento de coleta e análise dos dados

As entrevistas foram realizadas em horários e locais (universidade, residência ou ambiente de trabalho) previamente combinados por telefone, a partir do consentimento da pessoa em participar da amostra de pesquisa após esclarecimentos sobre os objetivos destas, a acessibilidade dos resultados aos participantes e o tratamento coletivo dos dados para evitar a identificação dos indivíduos. Tais entrevistas foram gravadas com permissão do entrevistado e transcritas visando à análise de conteúdo temática das respostas (Bardin, 2000), análise essa que abrangeu as seguintes etapas: planejamento e organização da análise, categorização das respostas, registro, em forma de banco de dados, do programa de informática SPSS for Windows e análise estatística por meio do referido programa.

\section{Resultados e discussão}

Nesta secção, apresentam-se os resultados das análises de conteúdo em duas formas integradas: uma qualitativa, através de categorias 
de respostas construídas pelo pesquisador na transcrição das entrevistas, e outra, quantitativa, a partir da freqüência com que as respostas aparecem ou não na verbalização dos jovens entrevistados. A apresentação de tais resultados encontra-se dividida em subsecções, que seguem a ordem dos itens do roteiro de entrevista.

\section{Percepção da transição Universidade-mercado de trabalho}

A partir da análise de conteúdo das vinte entrevistas, foi possível identificar doze categorias sobre o tema transição Universidade-mercado de trabalho na fala de dezenove jovens, conforme se visualiza na Tabela 1.

Tabela 1 - Categorias relacionadas à transição Universidade-mercado

\section{Atributos/síntese das respostas \\ Investimento na qualificação: pretensão}

de estudar mais, fazer pós-graduação, buscar

especializar-se em uma área, participar de cursos.

Competitividade: competição entre

Falta de oportunidade: não oferecimento de trabalho a recém-formados/inexperientes.

Qualificação: importância do currículo, do estágio ou da graduação na preparação para o trabalho. 06

11,5

Momento de decisão: definição da área de atuação.

Saber o que quer em termos de trabalho.

Aprendizagem: aquisição ou aplicação de conhecimentos. Aprender coisas novas.

04

04

7,7

21,1

Desorientação: perda de referência ao sair da universidade.

Contribuição social: opção de realizar trabalho de conclusão de curso para a comunidade.

Desgaste: batalhar, superar obstáculos, sobrecarga de atividades.

Oportunidade: oferecimento de trabalho a recém-formados/inexperientes.

Busca de autonomia: caminhar sozinho no futuro. Incertezas: dúvida quanto ao caminho profissional ou às demandas futuras do mercado.

Infra-estrutura: necessidade de espaço físico para trabalhar.

Total

02

01

01

01
3,8

10,5

3,8

10,5

3,8

2,0

10,5

5,3

2,0

5,3

52

\begin{tabular}{|l|l|}
\hline 2,0 & 5,3 \\
\hline 100,0 & 268,5
\end{tabular}

Os atributos mais freqüentes foram investimento na qualificação (68,4\% de casos), competitividade $(36,8 \%)$, falta de oportunidade (36,8\%) e qualificação (31,6\%), como visualizado na Tabela 1.

Percebe-se que os jovens entrevistados, entre as categorias que aplicam para descrever o período de transição Universidade-mercado de trabalho, usam algumas que correspondem aos aspectos exigidos pelo mercado de trabalho em torno do perfil profissional de candidatos com nível superior às vagas nas 
organizações, tais como a abertura à aprendizagem, a manutenção da empregabilidade por meio da atualização constante (o investimento na qualificação) e o preparo técnico adquirido na graduação (a qualificação). Os jovens também aplicam categorias de respostas que explicitam vivências de sofrimento durante o período de transição, como a desorientação, o desgaste e a incerteza. Outras categorias revelam a percepção do ambiente interpessoal e de relação do iniciante com a realidade do mercado de trabalho percebida no período entre o estágio e o início da vida profissional, sendo essas categorias o contexto de competitividade e, por conseguinte, de falta de oportunidades ocasionada pela alta demanda por vagas no mercado de trabalho. A categoria momento de decisão, por sua vez, representa o sentido construído pelos participantes sobre a experiência de tentar iniciar-se no mercado de trabalho.

Tomando-se cada categoria referente à transição universidade-mercado de trabalho e dividindo-se a amostra por grau universitário e aplicando-se o teste qui-quadrado, não houve rejeição de independência para nenhuma das categorias. Isso significa que os jovens entrevistados não se diferenciam quanto às categorias que aplicam para falarem sobre a transição Universidade-mercado de trabalho quando divididos por grau universitário. Logo, a percepção do momento de transição independe do fato de o jovem ser recém-graduado ou graduando.

\section{Avaliação da universidade}

Na avaliação da universidade, foram identificadas catorze categorias diferentes na fala de dezenove jovens, a partir da análise de conteúdo das vinte entrevistas, sendo onze categorias consideradas avaliações negativas e três avaliações positivas; conforme visualizado na Tabela 2. Entre as avaliações negativas da Universidade, aquelas que se apresentaram com maior freqüência foram: a inadequação na preparação para o mercado de trabalho $(47,4 \%)$, a falta de integração entre a teoria e a prática $(26,3 \%)$ e a falta de preparo para a rotina de trabalho $(21,1 \%)$. Por outro lado, alguns jovens fizeram uma avaliação positiva da Universidade com relação aos seguintes aspectos: oportunidade de conhecer e/ou escolher uma área de atuação (5,3\%), meio de qualificação (5,3\%) e suporte para o desempenho do trabalho $(5,3 \%)$.

Tabela 2 - Avaliação da Universidade pelos jovens

\begin{tabular}{|c|c|c|c|}
\hline Avaliação da universidade & \multirow[t]{2}{*}{ Freqüência } & \multirow{2}{*}{$\begin{array}{l}\text { Proporção } \\
\text { por respostas }\end{array}$} & \multirow{2}{*}{$\begin{array}{l}\text { Proporção } \\
\text { por casos }\end{array}$} \\
\hline Negativa & & & \\
\hline Inadequada na preparação para o mercado & 09 & 27,3 & 47,4 \\
\hline Sem integração teoria-prática & 05 & 15,2 & 26,3 \\
\hline Não prepara para a rotina de trabalho & 04 & 12,1 & 21,1 \\
\hline Não incentiva a prática & 03 & 9,1 & 15,8 \\
\hline Transmite apenas conhecimento básico & 02 & 6,1 & 10,5 \\
\hline Sem condições de dar toda experiência prática & 02 & 6,1 & 10,5 \\
\hline Não informa às empresas sobre seus recém-formados & 01 & 3,0 & 5,3 \\
\hline Não divulga o papel dos profissionais para o mercado & 01 & 3,0 & 5,3 \\
\hline Lenta na transmissão do saber & 01 & 3,0 & 5,3 \\
\hline Desprestigiada político-cientificamente & 01 & 3,0 & 5,3 \\
\hline Deveria favorecer a definição por uma área & 01 & 3,0 & 5,3 \\
\hline Positiva & & & \\
\hline Oportunidade de conhecer/escolher área & 01 & 3,0 & 5,3 \\
\hline Meio de qualificação & 01 & 3,0 & 5,3 \\
\hline Suporte para o trabalho & 01 & 3,0 & 5,3 \\
\hline Total & 35 & 100,0 & 184,2 \\
\hline
\end{tabular}


Há uma freqüência maior de avaliações negativas, o que implica uma postura crítica do jovem e de uma vivência de insatisfação frente ao seu momento de transição em virtude da proximidade com o mercado de trabalho proporcionada pelos estágios ou pela auto-avaliação de seu preparo para o trabalho. A partir da percepção desses jovens pesquisados, faz-se mister enfatizar a importância de a Universidade repensar o seu papel diante das transformações no mundo do trabalho, no sentido de levar em conta questões relevantes enfrentadas pelos jovens no mercado de trabalho atual, que necessitam ser refletidas criticamente durante o seu processo de formação e incluir, como parte de suas atividades acadêmicas, projetos voltados para a inserção do graduando no mercado de trabalho, considerando as vivências dos jovens nesse período de transição entre o momento do estágio ou de finalização do curso de graduação e a entrada no mercado de trabalho, a fim de que ele tenha maior suporte institucional.

Por outro ângulo de visão, as categorias utilizadas pelos jovens entrevistados revelam também uma visão estrita da Universidade como uma instituição limitada à formação de profissionais para o mercado. Essa observação põe em tela a necessidade de uma discussão mais aprofundada com o estudante de nível superior sobre o papel da Universidade. Pode-se estar cobrando da instituição ou criticando-a, como se ela fosse a única responsável. É importante aqui deixar o questionamento sobre o fato de o preparo para o mercado de trabalho nos moldes cobrado pelos jovens ser da competência das universidades ou das organizações. Não haveria uma dificuldade de delimitar o papel de formação das universidades com a capacitação e o treinamento que as organizações devem oferecer?

Tomando-se cada categoria referente à avaliação da Universidade e dividindo-se a amostra por grau universitário, na aplicacão do teste qui-quadrado, não houve rejeição de independência para nenhuma das categorias. Assim, comprova-se que o tipo de avaliação que o jovem possui da Universidade independe dos grupos considerados dos quais faz parte.

\section{Avaliação do mercado de trabalho}

Uma pergunta específica do roteiro de entrevista se referia à percepção do jovem em torno da realidade do mercado de trabalho, sendo, então, identificadas sete categorias de avaliação realizadas sobre o mesmo por catorze jovens entre os vinte entrevistados, conforme visualizado na Tabela 3.

Entre os jovens entrevistados, 35,7\% avaliaram que o mercado de trabalho se encontra mais exigente quanto à questão da qualificação, como também diminui e extingue empregos. Outros jovens mencionaram a dinamicidade das ocupações (28,6\%), a difícil entrada no mercado $(21,4 \%)$ e a competitividade deste $(14,3 \%)$ como aspectos negativos. 
Tabela 3 - Avaliação do mercado de trabalho pelos jovens

\begin{tabular}{|l|c|c|c|}
\hline $\begin{array}{l}\text { Avaliação do mercado de trabalho } \\
\text { Negativa }\end{array}$ & Freqüência & $\begin{array}{c}\text { Proporção } \\
\text { por respostas }\end{array}$ & $\begin{array}{c}\text { Proporção } \\
\text { por casos }\end{array}$ \\
\hline Maior exigência de qualificação & 05 & 23,8 & 35,7 \\
\hline Diminuição/extinção de empregos & 05 & 23,8 & 35,7 \\
\hline Mercado dinâmico nas profissões & 04 & 19,0 & 28,6 \\
\hline Difícil entrada & 03 & 14,3 & 21,4 \\
\hline Competitivo & 02 & 9,5 & 14,3 \\
\hline Positiva & & & \\
\hline Aberto para quem se informa & 01 & 4,8 & 7,1 \\
\hline Tem trabalho, não tem emprego & 01 & 4,8 & 7,1 \\
\hline Total & 21,0 & 100,0 & 150,0 \\
\hline
\end{tabular}

Dessa forma, é possível perceber que os jovens têm enfrentado os obstáculos atuais, advindos da reestruturação produtiva, e estão conscientes desse fato. É importante observar que, entre as categorias aplicadas nas avaliações negativas do mercado de trabalho, se repetem categorias já observadas quando os entrevistados falavam sobre o período de transição. Isso ocorre porque a ótica dos entrevistados sobre o mercado de trabalho se baseia em suas experiências com o período de transição. Além disso, é importante compreender que a percepção que têm do mercado de trabalho provavelmente deve estar relacionada com os aspectos que esses jovens demandam da Universidade.

Alguns avaliaram positivamente o mercado de trabalho, apontando o fato de existir oferta de trabalho, apesar de não haver emprego $(7,1 \%)$, e abertura do mercado para oferecer a informação a aqueles que são pró-ativos $(7,1 \%)$. Apesar do conteúdo positivo dessas categorias em relação ao mercado de trabalho, é importante assinalar que elas põem mais a responsabilidade sobre o jovem em conseguir se inserir no mercado do que neste em oferecer oportunidades adequadas.

As avaliações positivas revelam uma tentativa do jovem de acompanhar as demandas do mercado a partir da elaboração de projetos de carreira voltados para o trabalho autônomo, o que implicaria a prestação de serviços terceirizados ou a necessidade de elaborar um plano para a implantação de seu próprio empreendimento, caso tenha ajuda financeira da família; estar preocupado em formar e manter uma rede de relacionamento e utilização de tecnologias de informação (internet), além de outras estratégias que favoreçam o surgimento de oportunidades de trabalho. Esses aspectos das avaliações positivas revelam também uma mudança na juventude no sentido de diminuição da expectativa por um emprego.

O tipo de avaliação do mercado de trabalho independe de o jovem ser graduando ou recém-graduado, uma vez que, dividindo-se a amostra por grau universitário e aplicando-se o teste qui-quadrado para cada categoria referente à avaliação do mercado de trabalho, não houve rejeição de independência para nenhuma das categorias estudadas.

\section{Percepção das dificuldades para conseguir emprego}

Quanto à percepção sobre as dificuldades para conseguir emprego, entre as respostas categorizadas a partir da fala de dezoito jovens, mais freqüentemente estão: a falta de experiência $(33,3 \%)$, não buscar 
trabalho e não ter objetivos (22,2\%), má preparação, desatualização e desqualificação (16,7\%), como visualizado na Tabela 4.

Tabela 4 - Dificuldades para conseguir emprego

\begin{tabular}{|l|l|l|l|}
\hline Dificuldades para conseguir emprego & Freqüência & $\begin{array}{c}\text { Proporção } \\
\text { por respostas }\end{array}$ & $\begin{array}{c}\text { Proporção } \\
\text { por casos }\end{array}$ \\
\hline Individuais & & & \\
\hline Falta de experiência & 06 & 18,8 & 33,3 \\
\hline Não buscar & 04 & 12,5 & 22,2 \\
\hline Não ter objetivos & 04 & 12,5 & 22,2 \\
\hline Estar desatualizado & 03 & 9,4 & 16,7 \\
\hline Estar desqualificado & 03 & 9,4 & 16,7 \\
\hline Falta de recursos próprios para qualificação & 01 & 3,1 & 5,6 \\
\hline Incapacidade para trabalho em grupo & 01 & 3,1 & 5,6 \\
\hline Ambientais & & & 16,7 \\
\hline Má preparação na universidade & 03 & 9,4 & 5,6 \\
\hline Relações interpessoais negativas & 01 & 3,1 & 5,6 \\
\hline Incerteza da demanda futura do mercado & 01 & 3,1 & 5,6 \\
\hline Mercado desfavorável & 01 & 3,1 & 5,6 \\
\hline Falta de apoio social & 01 & 3,1 & 5,6 \\
\hline Desproporção salário-qualificação & 01 & 3,1 & 5,6 \\
\hline Não ter os critérios solicitados & 01 & 3,1 & 5,6 \\
\hline Desproporção oferta-demanda & 01 & 3,1 & 178,2 \\
\hline Total & 32 & 99,9 & \\
\hline
\end{tabular}

Os jovens pesquisados percebem, mais freqüentemente, as categorias individuais como dificuldades para conseguir emprego, dando maior ênfase à responsabilidade do indivíduo para a inserção no mercado de trabalho do que propriamente ao contexto econômico, político e social do País. Se os jovens aprendessem a planejar a sua carreira antecipando-se às tendências do mercado de trabalho, provavelmente, reduziriam as suas vivências de angústia e incertezas e se tornariam mais próativos, buscando ter uma visão de oportunidades ligadas ao trabalho e não necessariamente ao emprego, o que os tornaria mais empreendedores em seus projetos de carreira. Indaga-se, então: a quem compete ensiná-los a planejar a sua carreira, principalmente quando ainda não têm experiência de trabalho formal?

A própria Universidade nem sempre articula a vida acadêmica dos seus universitários e a futura experiência profissional destes a partir do seu ingresso, com a intenção de prepará-los não só tecnicamente, mas também em termos comportamentais, para o mercado de trabalho. Observa-se, entretanto, que alguns jovens pesquisados buscam preencher as deficiências individuais fora da Universidade (por exemplo: realizando cursos técnicos, estagiando voluntariamente em organizações, etc.), o que permite a alguns obter mais qualificação técnica necessária para o exercício de sua profissão. A competitividade, provavelmente, tem levado o jovem a assumir sua própria formação técnica antecipadamente, minimizando a responsabilidade das organizações em investir em qualificação e capacitação.

Dividindo-se a amostra por grau universitário e aplicando-se o teste qui-quadrado para cada categoria referente às dificuldades de conseguir emprego, não houve rejeição de independência para nenhuma 
das categorias. Em outras palavras, a percepção das dificuldades para conseguir emprego independe de o jovem ser graduando ou recém-graduado.

\section{Percepção das facilidades para conseguir emprego}

Outra pergunta respondida pelos vinte jovens se referia à percepção sobre as facilidades para conseguir emprego, sendo identificadas catorze categorias nas respostas (Tabela 5). A maior freqüência de casos (50\%) apareceu na categoria "contatos sociais", seguida por "oportunidade de ter experiência anterior" e "atitude de busca" (45\%) e por "conhecimentos teóricos adquiridos" (35\%).

Tabela 5 - Facilidades para conseguir emprego

\begin{tabular}{|l|c|c|c|}
\hline Facilidades para conseguir emprego & Freqüência & $\begin{array}{c}\text { Proporção } \\
\text { por respostas }\end{array}$ & $\begin{array}{c}\text { Proporção } \\
\text { por casos }\end{array}$ \\
\hline Individuais & & 18,4 & 45,0 \\
\hline Atitude de busca & 09 & 14,3 & 35,0 \\
\hline Conhecimentos adquiridos & 07 & 4,1 & 10,0 \\
\hline Segurança do papel profissional & 02 & 4,1 & 10,0 \\
\hline Apresentação pessoal & 02 & 4,1 & 10,0 \\
\hline Atualizar-se & 02 & 4,1 & 10,0 \\
\hline Ter desenvoltura & 02 & 2,0 & 5,0 \\
\hline Ter objetivos & 01 & 2,0 & 5,0 \\
\hline Escolha do campo de atuação & 01 & 2,0 & 5,0 \\
\hline Ter conhecimento prévio do mercado & 01 & 2,0 & 5,0 \\
\hline Saber agregar pessoas & 01 & & \\
\hline Ambientais & & 20,4 & 50,0 \\
\hline Contatos sociais & 10 & 18,4 & 45,0 \\
\hline Oportunidade de ter experiência anterior & 09 & 2,0 & 5,0 \\
\hline Surgir a oportunidade de trabalho & 01 & 2,0 & 5,0 \\
\hline Ter os critérios solicitados & 01 & 100,0 & 245,0 \\
\hline Total & 49 & & \\
\hline
\end{tabular}

Dividindo-se os participantes por grau universitário, não houve rejeição de independência pelo teste qui-quadrado entre o grau universitário do jovem e cada uma das categorias referentes às facilidades para conseguir emprego. Logo, a percepção quanto às facilidades para conseguir emprego independe do fato de o jovem ser recém-graduado ou graduando.

Embora as duas facilidades mais freqüentemente mencionadas pelos jovens sejam categorias ambientais, foram aplicadas mais categorias individuais, provavelmente por terem melhor controle sobre elas. É importante ressaltar que a pró-atividade e o domínio da informação, destacados como elementos facilitadores para conseguir emprego, refletem, novamente, tanto a perspectiva do mercado quanto o perfil do novo trabalhador, assim como o fato de ser ter experiência prática e de se poder contar com uma rede de relacionamentos. Assim, na opinião desses jovens, os graduandos que tivessem tais características seriam aqueles com possibilidade de sucesso na transição para o mercado de trabalho. 


\section{Imagem da profissão}

A partir da fala de dezoito jovens entrevistados, foi possível categorizar dezessete atributos sobre o tema imagem da profissão, sendo que doze categorias se referiam a uma imagem negativa, e cinco, a uma imagem positiva, conforme se visualiza na Tabela 6 . É importante mencionar que não havia uma pergunta específica sobre a imagem da profissão no roteiro da entrevista; no entanto, à medida que se perguntava sobre a Universidade e o mercado de trabalho, os jovens entrevistados relatavam a imagem que tinham da sua profissão.

Entre as categorias de maior freqüência de respostas (30 a 40\% dos casos), estavam aquelas correspondentes a uma imagem negativa da profissão: "mercado competitivo" e "necessidade de maior preparação para o mercado". É importante ressaltar também uma freqüência de respostas de $22,2 \%$ dos casos para "mercado desfavorável". Quanto à imagem positiva da profissão, pode-se destacar a categoria "mercado favorável", com 33,3\% dos casos.

Tabela 6 - Imagem da profissão

\begin{tabular}{|l|l|l|l|}
\hline Imagem da profissão & Freqüência & Proporçãopor respostas & Proporção por casos \\
\hline $\begin{array}{l}\text { Negativa } \\
\text { Mercado competitivo }\end{array}$ & 07 & 14,0 & 38,9 \\
\hline $\begin{array}{l}\text { Necessidade de maior preparação } \\
\text { Mercado desfavorável }\end{array}$ & 06 & 12,0 & 33,3 \\
\hline $\begin{array}{l}\text { Pouco conhecida pela sociedade } \\
\text { Necessidade de diferencial para }\end{array}$ & 04 & 8,0 & 22,2 \\
\hline se destacar & 03 & 6,0 & 16,7 \\
\hline Grupos fechados & 03 & 6,0 & 16,7 \\
\hline Pouco retorno financeiro & 02 & 6,0 & 16,7 \\
\hline Elitizada pela sociedade & 02 & 4,0 & 11,1 \\
\hline Tendência à queda & 02 & 4,0 & 11,1 \\
\hline Instável em renda & 01 & 4,0 & 11,1 \\
\hline Tendência à especialização pela & & 2,0 & 5,6 \\
\hline velocidade de novas informações & 01 & 2,0 & 5,6 \\
\hline Desacreditada pela sociedade & 01 & 2,0 & 5,6 \\
\hline Positiva & & & 33,3 \\
\hline Mercado favorável & 06 & 12,0 & 16,7 \\
\hline Valorizada pela sociedade & 03 & 6,0 & 16,7 \\
\hline Atual (da moda) & 03 & 6,0 & 11,1 \\
\hline Deve caminhar para o trabalho & & & 5,6 \\
\hline em equipe & 02 & 4,0 & 277,8 \\
\hline Tendência à subida & 01 & 2,0 & \\
\hline Total & 50 & 100,0 & \\
\hline
\end{tabular}

Dividindo-se a amostra por grau universitário, não houve rejeição de independência pelo teste quiquadrado entre cada uma das categorias relacionadas à imagem da profissão e ao grau universitário do jovem. A percepção da imagem da profissão independe do fato de o jovem ser recém-graduado ou graduando. 
A necessidade de maior preparação para o trabalho seria uma forma de lidar com a competitividade percebida no momento de entrada no mercado. A variação quanto à percepção de um mercado ora favorável, ora desfavorável, acontece por haver diferentes áreas profissionais ocupadas por esses jovens e haver, portanto, diferentes experiências de transição nessa etapa de sua vida.

\section{Projetos futuros de trabalho}

Uma pergunta do roteiro de entrevista se referia aos projetos futuros de trabalho do jovem. As respostas não eram excludentes, podendo o jovem discorrer livremente sobre os seus projetos; assim sendo, a partir da fala de dezoito jovens, surgiram quatro categorias (Tabela 7). Em ordem decrescente de freqüência de respostas, uma percentagem de $61,1 \%$ dos jovens apresentou, como projeto futuro, $\mathrm{O}$ "trabalho autônomo"; em seguida, a "capacitação profissional", com 44,4\%; o "emprego em instituição pública", com 33,3\%, e o "emprego em instituição particular, com 22,2\%.

Tabela 7 - Projetos futuros de trabalho dos jovens

\begin{tabular}{|l|c|c|c|}
\hline Projetos futuros de trabalho & Freqüência & Proporção por respostas & Proporção por casos \\
\hline Trabalho autônomo & 11 & 37,9 & 61,1 \\
\hline Capacitação profissional & 08 & 27,6 & 44,4 \\
\hline Emprego em instituição pública & 06 & 20,7 & 33,3 \\
\hline Emprego em instituição particular & 04 & 13,8 & 22,2 \\
\hline Total & 29 & 100,0 & 161,1 \\
\hline
\end{tabular}

Assim, quanto aos seus projetos futuros, a maioria dos jovens desejava ser trabalhador autônomo. Quando, ao fazer o cruzamento entre as categorias (crosstabs), a categoria "trabalho autônomo" estava mais associada à categoria “capacitação profissional” (36,4\%) do que as demais $(18,2 \%)$, verificouse que estas, porém, não eram excludentes, podendo o sujeito mencionar mais de uma. Em decorrência disso, havia maior percentagem de jovens que desejavam ser trabalhadores autônomos e, ao mesmo tempo, fazer uma pós-graduação do que somente trabalhar como autônomos ou serem empregados em instituição particular ou pública.

Nesse grupo de jovens, o desejo de ser um profissional liberal aliado ao aumento do desemprego e à instabilidade no emprego somente intensifica a busca pelo trabalho autônomo associado à capacitação profissional, visando assim, a garantir uma clientela - seja pela qualidade dos serviços oferecidos, seja pela obtenção de um diferencial competitivo.

\section{Conclusões}

As análises realizadas contribuíram para responder às questões de pesquisa apresentadas anteriormente. À medida que se desenvolveram tais análises, elucidaram-se as semelhanças entre os jovens, na transição de estudante universitário a profissional, quanto à percepção sobre:

(1) A transição Universidade-mercado de trabalho. A maioria dos jovens percebe a necessidade de investimento na sua qualificação, o que implica duas possibilidades: abrir mão de um trabalho e continuar os estudos através de uma pós-graduação, tendo uma independência parcial, ou conciliar estudo e trabalho, adiando, assim, a sua independência plena. Assim, esses jovens seguem o que 
diversos atores citados anteriormente (Margulis, 2001; Sanchis, 1997; Agulló-Tomás, 1997) apontam como característico da juventude: o prolongamento desse período para alcançar a vida adulta em virtude da continuação dos estudos. Assim, observa-se que a transição Universidade-mercado de trabalho às vezes termina no caminho de volta, ou seja, do mercado de trabalho para a Universidade, quando o jovem resolve fazer uma pósgraduação.

(2) A avaliação da universidade. Quase metade dos jovens entrevistados indicou a falta de preparação para o mercado de trabalho, o que reforça o comportamento de continuar a investir em sua qualificação e aponta o questionamento sobre a proximidade da Universidade com aquele setor. Os resultados encontrados também apontam a necessidade de indagar e discutir o papel da própria Universidade. São necessárias políticas públicas que exijam das organizações/ empresas investimentos em educação/ qualificação do trabalhador, incluindo os jovens iniciantes.

(3) A avaliação do mercado de trabalho. A maior exigência de qualificação e redução de empregos éa realidade que alguns jovens esperam vivenciar no mercado de trabalho; portanto, essas características também favorecem a busca por investimento na qualificação para o alcance de expectativas de um mercado restrito e para ter um diferencial neste.

(4) Dificuldades e facilidades para conseguir o emprego. Os jovens investigados apontam as dificuldades de conseguir empregos em categorias tais como: falta de oportunidade, de atitude de busca e de conhecimentos teóricos. Enquanto isso, as facilidades seriam justamente a presença desses aspectos. $\mathrm{O}$ destaque de fatores individuais, mais do que ambientais, pode, por um lado, ocasionar sofrimento psíquico àquele jovem que deposita em si próprio a responsabilidade pelo seu sucesso e fracasso no mercado e, por outro lado, pode incentivar a pró-atividade. Por isso, as sugestões mencionadas por Gazo-Figuera (1996) no âmbito da orientação universitária são cruciais. O trabalho com grupos de interesse evitaria o isolamento do jovem ao enfrentar os problemas advindos da sua relação com o mercado de trabalho. É importante relembrar que a metade dos jovens entrevistados nomeou os contatos sociais como um dos mais importantes apoios para conseguir emprego. Assim, a indicação ainda exerce influência decisiva no alcance do emprego, ou seja, entre os candidatos às vagas de mercado de trabalho, aquele com maior rede de relacionamentos tem seu diferencial competitivo.

(5) Imagem da profissão. Quando os jovens mencionavam o mercado de trabalho na sua profissão, relatavam, com maior freqüência, uma imagem negativa relacionada à competição e à falta de preparo. As diferenças que ocorreram quanto ao mercado de trabalho favorável ou desfavorável justificam-se apenas quando os jovens são divididos por curso de graduação.

(6) Projetos futuros de trabalho. A maioria dos jovens revela ter, como projeto futuro, o trabalho autônomo (prestador de serviços ou profissional liberal). Essa seria uma alternativa de obter um trabalho (sem vínculo empregatício) diante da escassez de empregos.

Em síntese, os jovens entrevistados apresentam invariabilidade de percepção quanto aos aspectos tratados anteriormente quando divididos por grau universitário, ou seja, não foi observada diferença em nenhum dos domínios pesquisados entre os participantes. Tal invariabilidade revela que a realidade dos estágios pelos quais estes passam antes de se tornarem profissionais com nível superior pode favorecer uma visão mais realista do mercado de trabalho e uma avaliação mais crítica da universidade diante de um momento decisivo como esse, de transição, havendo, portanto, uma semelhança entre as vivências dos grupos de jovens investigados. 
Tal invariabilidade certamente é coerente com as noções de uma juventude que se prolonga, como abordado na literatura. No entanto, diferenças podem ser encontradas caso sejam comparados, em novas pesquisas, jovens graduandos com jovens graduados já com inserção plena no mercado de trabalho.

Observou-se também que é provável existir diferenças marcantes entre as áreas de graduação. O grupo de jovens entrevistados vinha de diferentes áreas; no entanto, devido às características exploratórias da presente pesquisa, não se contava com o número de participantes que permitisse alguma inferência nesse aspecto. Fica, então, a sugestão de novos estudos que focalizem a área de formação do jovem.

Percebe-se ainda que a Universidade poderia desenvolver projetos de extensão e pesquisa mais coerentes com as necessidades do mercado de trabalho, introduzindo o jovem mais cedo no contexto em que irá atuar como profissional e preparando-o em aspectos psicossociais (identidade profissional, imagem pessoal, socialização organizacional, etc.), que interferem no projeto da carreira, o que poderia desenvolver a sua empregabilidade. Assim, a Universidade poderia oferecer um programa de orientação profissional e de preparo para o trabalho, uma vez que muitos jovens mudam de curso ou pela falta de maturidade para a escolha da profissão ou pelas oportunidades que vão aparecendo na sua vida, e, além disso, a falta de preparo para a entrada no mercado de trabalho está associada às competências humanas, e não somente às técnicas.

A política de geração de empregos no País poderia contemplar esses grupos de jovens, no sentido de garantir a experiência do primeiro emprego pelo incentivo a programas de inserção profissional desenvolvido pelas organizações. As políticas públicas para a juventude deveriam levar em conta o entendimento dos autores sobre o conceito do que seja ser jovem hoje. Tendo essa compreensão, o governo poderia adotar políticas dirigidas a vários grupos de jovens, respeitando as especificidades e as necessidades daí decorrentes, e não simplesmente implementar alguns programas que apenas beneficiam uma parcela da juventude (dentro do limite de uma faixa etária) sem levar em conta as características atuais, tal como o seu prolongamento. Dentro desse enfoque das especificidades da juventude, poderia se questionar: Por que o Brasil não adota o programa Primeiro Emprego para os jovens recém-egressos das universidades? Por que não exigir que as empresas invistam no desenvolvimento do seu quadro funcional atual através de convênios com as universidades, dentro de uma política de responsabilidade social? Por que a Universidade não conscientiza e incentiva os jovens a utilizar os seus espaços (centros acadêmicos, por exemplo) para favorecer a sua organização social? Enfim, sabendo que o assunto não se esgota aqui, deixa-se este momento para a reflexão sobre o jovem universitário e a sua transição para o mercado de trabalho. 
Simone Lopes de Melo Faculdade de Ciências, Cultura e Extensão do RN Mestrado em Psicologia pela Universidade Federal do Rio Grande do Norte.

Livia de Oliveira Borges Universidade Federal do Rio Grande do Norte. Pós-doutorado em Psicologia social do trabalho pela Faculdade de Ciências Políticas e Sociológicas na Universidade Complutense de Madrid.

Faculdade de Ciências, Cultura e Extensão do RN - FACEX - Rua Orlando Silva, 2897 - Capim Macio CEP 59080-020 - Natal, RN, Brasil. Telefone: (84) 3235.1415

AGULLÓ-TOMÁS, E. Jóvenes, Trabajo e Identidad. Oviedo: Universidad de Oviedo, 1997

ARAÚJO, J. S.; SARRIERA, J.C. Redirecionamento da Carreira Profissional: uma Análise Compreensiva. In: Sarriera, J. C.; Rocha, K. B.; Pizzinato, A. (org.). Desafio do Mundo do Trabalho: Orientação, Inserção e Mudanças. Porto Alegre: EDPUCRS, 2004, pp.135-57.

BARDIN, L. Análise de Conteúdo. Lisboa: Edições 70, 2000.

BERCOVICH, A.; MADEIRA, F. A. "Onda Jovem" e seu Impacto na População Economicamente Ativa de São Paulo. Planejamento e Políticas Públicas, São Paulo, v. 8, pp. 1-28, 1992.

CAMARANO, A. A.; MELIO, J.L.; PASINATO, M.T.; KANSO, S. Caminhos para a Vida Adulta: as Múltiplas Trajetórias dos Jovens Brasileiros. Rio de Janeiro: Instituto de Pesquisa Econômica Aplicada, 2004. Disponíve em: http://www.dominiopublico.gov.br/download/texto/td 1038.pdf. Acesso em: 01 jul.2005.

CARDOSO, R. C. L.; SAMPAIO, H.M. S. Bibliografia sobre a Juventude São Paulo: Editora da Universidade de São Paulo, 1995.

COSTA, A. C. G. Protagonismo Juvenil: Adolescência, Educação e Participação Democrática. Minas Gerais: Fundação Odebrecht, 1996, pp. 9-68.

ERICKSON, E. Identidade, Juventude e Crise. Rio de Janeiro: Zahar Editores, 1976.

GAZO-FIGUERA, P. La Inserción del Universitario en el Mercado de Trabajo. Barcelona: EUB, 1996.

IBGE. População Jovem no Brasil. Rio de Janeiro, 1999. Disponível em: http//:www.ibge.gov.br/home/estatística/populacao/ populacao jovem brasil/default.shtm Acesso em: 26 jul.2005.

Pesquisa Nacional por Amostra de Domicílios. Rio de Janeiro, 2003. Disponível em: http://www.ibge.gov.br/home/estatistica/ populacao/trabalhoerendimento/pnad2003/default.shtm Acesso em: 26 jul.2005
LAKATOS, E.M.; MARCONI, M.A. (1991). Técnicas de Pesquisa. In: Fundamentos de Metodologia Científica. São Paulo: Atlas, 1991, pp. $174-214$

MARGULIS, M. Juventud: una Aproximación Conceptual. In: Donas, S. (org.). Adolescencia y Juventud en América Latina. Cartago: Livro Universitário Regional, 2001, pp. 41-56.

MET. Programa Nacional de Estímulo ao Primeiro Emprego. Brasília 2004. Disponível em: http://www.mte.gov.br/FuturoTrabalhador/ primeiroemprego/Default.asp. Acesso em: 26 jul.2005.

QUAPPER-DUARTE, K. ¿juventud o Juventudes? Acerca de como Mira y Remirar a las Juventudes de nuestro Continente. In: Donas, S. (org.). Adolescencia y Juventud en América Latina. Cartago: Livro Universitário Regional, 2001, pp. 57-74

SAMPAIO, H; LIMONGI, F; TORRES, H. Eqüidade e Heterogeneidade no Ensino Superior Brasileiro. Brasília: Instituto Nacional de Estudose Pesquisas Educacionais, 2000. Disponível em: http:// www.publicacoes.inep.gov.br/. Acesso em: 01 jul.2005.

SANCHIS, E. Da Escola ao Desemprego. Rio de Janeiro: Agir, 1997.

SARRIERA, J. C.; VERDIN, R. Os Jovensà Procura do Trabalho: uma Análise Qualitativa. Revista PSICO, Porto Alegre, v. 27, n. 1, pp. 59-70, 1996.

SCHIESSL, C. S.; SARRIERA, J. C. A Entrada no Mundo do Trabalho: Preparação e Inserção. In: Sarriera, J. C.; Rocha, K. B.; Pizzinato, A. (org.). Desafio do Mundo do Trabalho: Orientação, Inserção e Mudanças. Porto Alegre: EDPUCRS, 2004, pp.33-72. 